\title{
An unusual foreign body in the preputial sac
}

\author{
A K Jaiswal
}

orgasm of the partner during intercourse is not

Abstract

A 28 year old Indian male presented with an unusual foreign body, a penicillin bottle containing tincture of iodine, in the preputial sac. The purpose of introducing the bottle was to tickle his glans penis as a form of masturbation. The bottle was so firmly impacted that it could be removed only under general anaesthesia.

\section{Introduction}

Occasionally, a case is encountered of such an unusual nature that it should be recorded to add to the existing information on the subject. I present what I believe to be the first reported case of a very peculiar foreign body in a very unusual site.

\section{Case Report}

A 28 year old male was admitted with a two hours history of pain and swelling of the penis. This had followed the self introduction of a penicillin bottle into his preputial sac. The purpose of introducing the bottle was to tickle his glans penis as a form of masturbation. The bottle became firmly impacted in the foreskin and he failed to remove it on repeated attempts. The patient admitted to a regular habit of masturbation and frequent visits to prostitutes. He denied having introduced such objects previously.

Examination revealed a stony hard subcutaneous swelling $5.5 \mathrm{~cm} \times 2.5 \mathrm{~cm}$ in the distal third of the penile shaft. Owing to phimosis no part of the bottle was visible but its outline could be palpated. The skin over the ends of the bottle was stretched thinly and showed bluish-black discoloration. No regional adenopathy was noted, and the rest of the physical examination was unremarkable. The presence of the glass bottle was confirmed by X-ray examination. Investigations pertaining to sexually transmitted diseases were normal.

The bottle could be removed only under general anaesthesia. It measured $5.5 \mathrm{~cm}$ long and $8 \mathrm{~cm}$ in circumference and contained tincture of iodine (fig). The mouth of the penicillin bottle was sealed with its rubber cap. A patch of vitiligo was noticed on the undersurface of prepuce. Psychiatric examination of the patient revealed no abnormality.
Discussion

Implantation of foreign bodies under the skin of the penis to enhance coital excitement and uncommon in south east and far east Asia. $\frac{\bar{v}_{4}}{\bar{c}}$ This practice appears to be quite common Thailand, the Philippines and Korea, where 3 is performed by unqualified people in prisofs and among lower social and economic groups. The procedure entails piercing the penile skith with a sharp instrument without local anaes thetic, and inserting one or more beads in the superficial fascia. The nodules that resiobt are usually asymptomatic and have been calleg artificial penile nodules. ${ }^{2}$ The most common substance used to make the spheres is derived from the bottom of glass containers of Tancho pomade, a brand of Japanese hair pomade widely used in South East Asia. ${ }^{3}$ Beside glass beads, other material such as pearls, jewe ivory and plastic balls are employed to produee artificial penile nodules. The size of the objects is usually $0.5 \mathrm{~cm}$ to $1.4 \mathrm{~cm}$ in diameter and the shape either round or oval.

Interestingly, no reference has been found कo a penile foreign body of such an unusual natume and size as seen in our patient. Moreover, in view of the anatomy of the foreskin, the site the present case was a very unusual one to have a foreign body of such a size. Lastly, in contrist

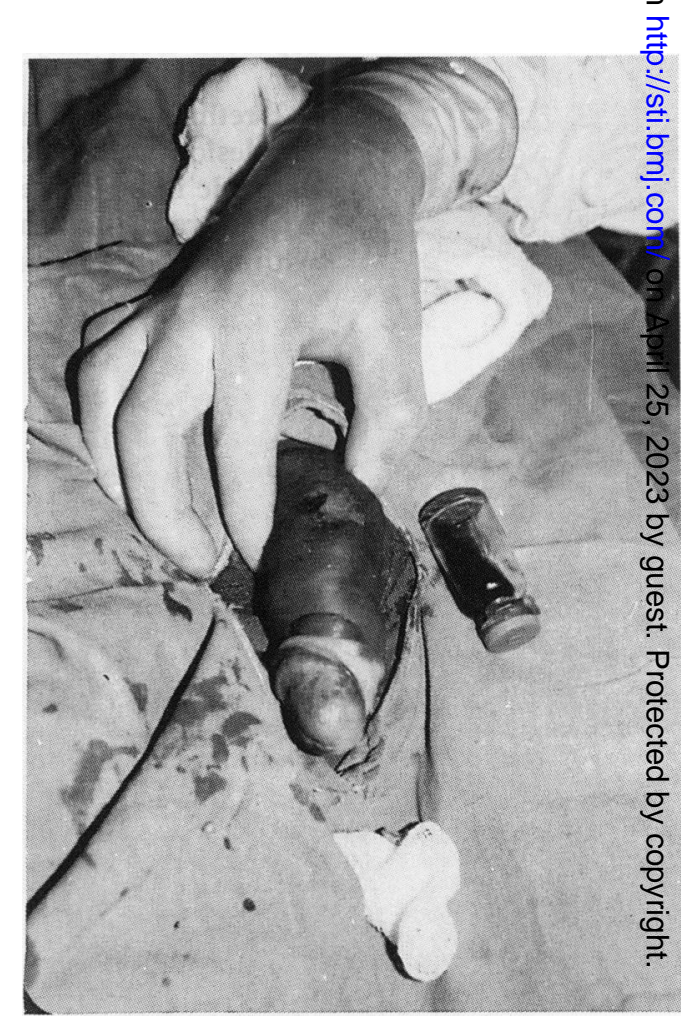

Figure Subcutaneous swelling on distal third of the penile shaft, and extracted sealed penicillin bottle containing tincture of iodine. 
to earlier reported cases where the object was inserted into the superficial fascia of the penis with the motive of enhancing sexual arousal of the female partner, our case introduced the object into the preputial sac with the motive of enhancing his own sexual excitement.
1 Lim KB, Seow CS, Tulip T, et al. Artificial penile nodules: case reports. Genitourin Med 1986;62:123-5.

2 Nitichandhaprabhas P. Artificial penile nodules: case reports from Thailand. Br f Urol 1975;47:463.

3 Sunderavej K, Suchato C. Tancho's nodules. Australas Radiol 1974;18:453-4.

4 Gilmore WA, Weigand DA, Burgdorf WHC. Penile nodules in South East Asian men. Arch Dermatol 1983;119: 446-7. 